\title{
A Gestão do Conhecimento como Estratégia Competitiva para a Gestão do Turismo: uma contribuição teórica
}

\section{Knowledge Management as a Competitive Strategy for Tourism Management: a theoretical contribution}

\section{La Gestión del Conocimiento como Estrategia Competitiva para la Gestión de Turismo: una contribución teórica}

Maria Emília Martins da Silva ${ }^{1}$

\begin{abstract}
Resumo
A gestão do conhecimento tem sido adotada como novo paradigma organizacional na sociedade contemporânea, mas no segmento de serviços, em especial no turismo, sua aplicabilidade ainda é incipiente. Esse modelo de gestãose apresenta como ferramenta estratégica, na explicitação do conhecimento tácito dos stakeholders, na valorização do capital intelectual e, finalmente, na contribuiçãode decisões realistas e criativas para o segmento. Neste viés, o objetivo do estudo foi analisar como a gestão do conhecimento e seus respectivos processos podem contribuir para a gestão estratégica do turismo, por meio de uma revisão da literatura. A abordagem metodológica esteve pautada no paradigma interpretativista, apoiando-se no método de pesquisa bibliográfica. A investigação desenvolveu-se em janeiro do ano de 2015. Os resultados apontaramque a gestão do conhecimento pode contribuir decisivamente para o sucesso de uma organização turística, uma vez que, por meio dela, utilizam-se de procedimentos sistemáticos para a criação, compartilhamento e disseminação do conhecimento entre os stakeholders, favorecendo a melhoria contínua dos processos outrora investidos. Além disso, os resultados teóricos demonstram contribuições substanciais da gestão do conhecimento como diferencial para a gestão estratégica do turismo, práticas inovadoras e de fácil implementação em destinos turísticos e empresas hoteleiras.Ainda, identificou-se que a maioria das publicações retratam estudos de caso em empresas do setor, em grande parte em países do Reino Unido e Ásia. Finalmente, a gestão do conhecimento e a adoção de seus princípios são considerados fundamentais para garantir qualidade, inovação e criatividade nas organizações turísticas, sustentando a competitividade da empresa.
\end{abstract}

Palavras-chave: Conhecimento; Revisão narrativa; Processos em gestão do conhecimento; Turismo.

\section{Abstract}

Knowledge management has been adopted as a new organizational paradigm in contemporary society, but in the service sector, especially tourism, its applicability is still incipient. This management model is presented as a strategic tool in explaining the tacit knowledge of stakeholders on the value of intellectual capital and, contribution of realistic and creative

\footnotetext{
${ }^{1}$ Doutoranda em Engenharia e Gestão do Conhecimento pela Universidade Federal de Santa Catarina. Docente do Curso de Tecnologia em Gestão do Turismo do Instituto Federal Catarinense - Campus Avançado Sombrio. Sombrio-SC, Brasil. E-mail: emilia@ifc-sombrio.edu.br
} 
decisions for the segment. The objective of the study was to analyze how knowledge management and their processes can contribute to the strategic management of tourism, through a literature review. The methodological approach was guided in the interpretive paradigm, based on literature method. The research was developed in January 2015. The results showed that knowledge management can contribute decisively to the success of a tourist organization, since we use systematic procedures for creating, sharing and dissemination of knowledge between stakeholders, promoting continuous improvement of processes once invested. In addition, the theoretical results demonstrate substantial contributions of knowledge management as a differential for the strategic management of tourism, innovative practices are easy to implement in tourist destinations and hotel companies. Still, it was found that most publications show studies in companies, normally in countries as the UK and Asia. Finally, knowledge management and the adoption of its principles are considered fundamental to ensure quality, innovation and creativity in tourist organizations, maintaining the company's competitiveness.

Keywords: Knowledge; Narrative review; Processes in knowledge management; Tourism.

\section{Resumen}

La gestión del conocimiento há sido adoptado como un nuevo paradigma de organización en la sociedad contemporánea, pero en el sector servicios, especialmente el turismo, su aplicabilidad es aún incipiente. Este modelo de gestión se presenta como una herramienta estratégica en la explicación del conocimiento tácito de las partes interésadas en el valor del capital intelectual y, por último, la contribución de las decisiones realistas y creativas para el segmento. Este sesgo, el objetivo del estudio fue analizar cómo la gestión del conocimiento y sus procesos pueden contribuir a la gestión estratégica del turismo, através de una revisión de la literatura. El enfoque metodológico fue guiado por el paradigma interpretativo, basándose en el método de la literatura. La investigación se desarrolló en enero de 2015. Los resultados mostraron que la gestión del conocimiento puede contribuir de manera decisiva al éxito de una organización de turismo, ya que, através de él, utilizamos procedimientos sistemáticos para crear, compartir y la difusión de conocimientos entre stakeholders, promoviendo la mejora continua de los procesos, una vez invertido. Además, los resultados teóricos de muestran contribución es sustanciales de la gestión del conocimiento como un diferencial para la gestión estratégica del turismo, prácticas innovadoras y fáciles de implementar en los destinos turísticos y las empresas hoteleras. Sin embargo, se encontró que la mayoría de las publicación es retratan estudios de caso en las empresas del sector, en su mayoría países del Reino Unido y Asia. Por último, la gestión del conocimiento y la adopción de sus principios se consideran fundamentales para garantizar la calidad, la innovación y la creatividad en las organizaciones turísticas, el mantenimiento de la competitividad de la empresa.

Palabras clave: Conocimiento; Revisión narrativa; Los procesos de gestión del conocimiento; Turismo.

\section{Introdução}

A implementação da Gestão do Conhecimento (GC) nas indústrias produtivas advém da década de 1980, sendo o conhecimento reconhecido como competência profissional, contrapondo os 
preceitos da indústria capitalista, até então, baseada no sistema de produção convencional da Administração Clássica, conhecida como a era Taylorista e Fordista (1916) (URIARTE, 2008; NONAKA; TAKEUCHI, 2008). Nesta evolução, muitas organizações multinacionais, sobretudo as americanas, europeias e asiáticas, ao final dos anos 1990 reconheceram a GC como uma nova prática empresarial baseada no capital intelectual (ENZ;CANINA; WALSH, 2006), tendo como premissa o "conhecimento" como fator de produção (DALKIR, 2005; URIARTE, 2008; NONAKA; TAKEUCHI, 2008).

O estudo e a prática da GC no segmento de turismo e hospitalidade ainda são incipientes frente às demais organizações produtivas que buscam inovação e criatividade nos seus processos de negócios(SHAW; WILLIAMS, 2009). Um exemplo é mencionado por Cooper et al. (2007). Segundo os autores, dados e informações são reconhecidos como elementos capazes de subsidiar as empresas na busca pela qualidade na prestação de serviços e, por consequência, alcançar a competitividade entre os destinos e empresas turísticas. Entretanto, tais elementos não têm tido a devida aplicação e importância por parte dos gestores da área de turismo. Isso ocorre simplesmente porque "não se registra o amplo conhecimento de suas informações e nem de suas respectivas fontes”. (MORAES; TERENCE; ESCRIVÃO FILHO, 2004, p. 28).

Davidson e Voss (2002), Ruhanen e Cooper (2004) eBeesley (2005) explicam que algumas empresas turísticas estão adotando os princípios da GC em seus processos gerenciais e, reconhecendo os resultados obtidos. De acordo com os autores, em uma economia baseada no conhecimento, a pesquisa é o elemento chave na gestão dos negócios, pois pressupõe decisões mais realistas frente às necessidades dos consumidores. Esses, por sua vez, a cada geração tornam-se mais exigentes, informados e experientes, tendo a tecnologia como ponto crucial de mudança no estilo de vida da sociedade do conhecimento, incluindo, sobretudo, o segmento do turismo. Assim, como meio de manter a competitividade na atual economia, faz-se urgente o reconhecimento e o aperfeiçoamento dos ativos tangíveis e intangíveis de toda organização, incluindo o capital estrutural (RUHANEN; COOPER, 2004; PYO, 2005; COOPER, 2006; HALLIN; MARNBURG, 2008).

Cooper et al. (2007) apontam aspectos que devem ser observados pelos gestores do turismo na atual sociedade do conhecimento. São eles: a globalização e a indústria criativa que submetem o mercado turístico a uma concorrência cada vez maior; a profissionalização do setor turístico requer a busca permanente de informações para desenvolver a gestão sustentável da atividade; e, mudanças externas nas organizações estão gerando trabalhadores autônomos com elevado 
nível de informação e conhecimento. Ruhanen e Cooper (2004) esclarecem que o turismo se apresenta como um dos principais setores econômicos do mundo e, por isso, deve se adaptar a tais mudanças. Eles sugerem que as organizações ligadas ao setor adotem técnicas de GC a fim de transformar a pesquisa empírica do turismo em propriedade intelectual. Somente assim, essas empresas se manterão competitivas em um mercado dinâmico e cada vez mais complexo.

Para Nonaka e Takeuchi (2008), a GC é compreendida como o processo de criar continuamente novos conhecimentos e disseminá-los na organização, perpetuando mudanças positivas na geração de ideias e protótipos de negócios, por meio da aplicação da cadeia de valor do conhecimento (WEGGEMAN, 1997; NONAKA; TAKEUCHI, 2008). Davidson e Voss (2002, p 32)propõem uma ampla definição de GC, na qual Cooper (2006, p. 51 apud HALLIN; MARNBURG, 2008, p. 367), inclui o turismo, como sendo: "gestão do conhecimento consiste na aplicação dos ativos de conhecimento disponível para a [o turismo] organização criar vantagem competitiva ".

Em suma, compreende-se que, a partir da criação e compartilhamento de dados e informações devidamente codificados, esses tendem a proporcionar aos gestores base sólida para o aperfeiçoamento de seus serviços e produtos. Ademais, pode-se favorecer a co-criação de novos negócios turísticos, o desenvolvimento de novos conceitos, produtos ou serviços em conjunto com os stakeholders, premissa esta que compete à gestão do conhecimento.

Com base neste contexto, a pesquisa teve por objetivo analisar como a gestão do conhecimento e seus respectivos processos podem contribuir para a gestão estratégica do turismo, a partir da revisão narrativa da literatura. $\mathrm{O}$ estudo buscou seu arcabouço teórico em pesquisas científicas publicadas em renomados journals, visando demonstrar a relevância da GC como vantagem competitiva para a gestão de empresas turísticas.

\section{Procedimentos Metodológicos}

O problema de pesquisa desta investigação suscitou indagar: Como a gestão do conhecimento pode contribuir para a gestão estratégica de empresas turísticas? Baseada nesta questão, o estudo caracterizou-se, quanto aos objetivos, em exploratório e descritivo (GIL, 2010), amparado pelo paradigma interpretativista (HUGHES, 1980).

O método de pesquisa adotado foi a pesquisa bibliográfica por meio da revisão narrativa de literatura, cujo objetivo foi conhecer o arcabouço teórico sobre a gestão do conhecimento e sua 
aplicabilidade na gestão estratégica doturismo. Rother (2007) esclarece que a revisão narrativa possibilita a aquisição e atualização do conhecimento sobre um determinado tema em curto período de tempo, sendo a mesma utilizada para descrever o estado da arte de um assunto específico, sob o ponto de vista teórico ou contextual.No intuito de sistematizar a busca de publicações e a análise dos dados, seguiram-se os ensinamentos de Botelho, Cunha e Macedo (2011) sobre o método da revisão integrativa - uma abordagem da revisão sistemática.

A busca de publicações foi realizada em 08 de janeiro de 2015, na base de dados Web of Science pela abrangência de informações que apresenta, como também pelo seu reconhecimento na comunidade científica. Não houve especificação das áreas de conhecimento e nem de intervalo de tempo. Nessa segunda etapa, realizou-se a pesquisa na base supracitada conforme os descritores previamente estabelecidos, adotando-se os termos tourism e "knowledge management", com o operador booleano "AND” para fazer a combinação das palavras chave e o símbolo "*” para que recuperassem qualquer sufixo. Os termos foram aplicados nos campos de pesquisa da base eletrônica, compondo: título, palavras-chave e resumo das publicaçõese, adotando-se o filtro “artigos de pesquisa empírica e de revisão”. O resultado dessa estratégia de busca gerou 39 resultados, constituindo base para análise inicial.

$\mathrm{Na}$ terceira etapa foram analisados os títulos e resumos do conjunto, excluindo as publicações que traziam no seu escopo temas como tecnologia e engenharia, periódicos que não fossem da área específica de turismo e, publicações não disponíveis na web. Desse refinamento de busca, chegou-se a apenas nove artigos publicados nos seguintes periódicos: Journal of Travel Research, Tourism Recreation Research, Tourism Management, Cornell Hospitality Report, Annals of Tourism Research, Estudios y Perspectivas en Turismo.

Na última etapa, os artigos foram lidos na íntegra e categorizados, constituindo a análise dos estudos na forma de quadros, apresentados na quarta seção. Na quinta seção foi apresentado a síntese do conhecimento, resultado dos nove artigos selecionados.

\section{Gestão do Conhecimento: contextualização inicial}

A GC é relativamente nova na sociedade capitalista pós-industrial, cujo valor da informação, serviços, assistência e distribuição aumentaram vertiginosamente a partir da década de 1980, passando a denominar-se sociedade do conhecimento. Esta teoria tem como referência autores 
como Peter Drucker (1970), Karl Erik Sveiby (1980) e mais atualmente IkujiroNonaka e HirotakaTakeuchi (1990) e Karl Wiig (1993).

Segundo Uriarte (2008), teóricos como Peter Drucker e Paulo Strassman observaram a crescente importância da informação e do conhecimento tácito e explícito como ativos valiosos de toda organização, contribuindo para a sustentação de uma nova sociedade - a sociedade do conhecimento. O mesmo autor ressalta que a década de 1980 foi marcada pelo reconhecimento do conhecimento como "competência profissional", sendo consequentemente difundida nas décadas subsequentes em países do Oriente e,posteriormente do Ocidente.

$\mathrm{Na}$ atual economia, o conhecimento tornou-se um fator de valor competitivo nas organizações, partindo do pressuposto que ele é reconhecido como vantagem estratégica quando associado a dados e informações junto às qualificações e ideias dos indivíduos. O conhecimento é um bem essencial que se tornou mais importante que a terra, trabalho ou capital na atual economia (URIARTE, 2008). Muitas das definições encontradas na literatura indicam que conhecimento é algo inerente ao ser humano. Por isso, sabendo-se que o cerne das organizações é formado por pessoas, compreende-se que o conhecimento está irradiado nas organizações por meio delas, ou seja, o chamado "capital intelectual” (SILVA, 2013).

Segundo Davenport e Prusak (1999) o conhecimento é compreendido por uma mistura de experiências, valores, informação contextual e insight experimentado, a qual proporciona a incorporação de novas experiências aos indivíduos e às organizações. Nonaka e Tackeuchi (1995, p. 58) definem conhecimento como "um processo humano, dinâmico de justificar a crença pessoal, em direção à verdade”. Ainda, Davenport e Prusak (1998, p.6), metaforicamente elucidam que "o conhecimento pode ser comparado a um sistema vivo, que cresce e se modifica à medida que interage com o meio ambiente". Na visão de Davidson e Voss (2002), o conhecimento é imprevisível; seu custo é sempre antecipado e; uma amostra de conhecimento pode ter muitos donos, assim como, ele pode estar em mais de um lugar a qualquer momento.

Alguns autores explicam que a compreensão do conceito de conhecimento passa pelo entendimento de elementos expressosem uma cadeia de valor, a qual é composta por dados, informação, conhecimento e competência.Os dados são considerados como um número, uma palavra, uma letra, sem qualquer relevância no tempo e no espaço, não há contexto significativo nenhum para eles, podem ser armazenados eletronicamente e são quantificáveis (DALKIR, 2005; URIARTE, 2008). Vieira sintetiza que: “o dado é um fragmento bruto e desarticulado da 
realidade" (1998 apud STRAUHS et al., 2012, p. 15). Já, quando os dados tornam-se informações, a partir de um processamento, convergindo num contexto significativo, parte-se para a compreensão do conhecimento, criando seu próprio contexto.

Segundo Davenport e Prusak (2003), a informação pressupõe agregação de valor aos dados, concedendo-lhes relevância e significado, para então transformar-se em informação útil, cujo objetivo é favorecer a tomada de decisão pelos gestores.Sveiby (1998) acresce que a competência individual é adquirida pela aquisição do conhecimento explícito, desenvolvimento de habilidades, experiência pessoal e profissional, julgamento de valor e relacionamento social. A Figura 1, adaptada por Silva (2013) de Silva, Sofner e Pinhão (2003) e Strauhs et al. (2012) ilustraa cadeia de valor e sumariza os conceitos apresentados:

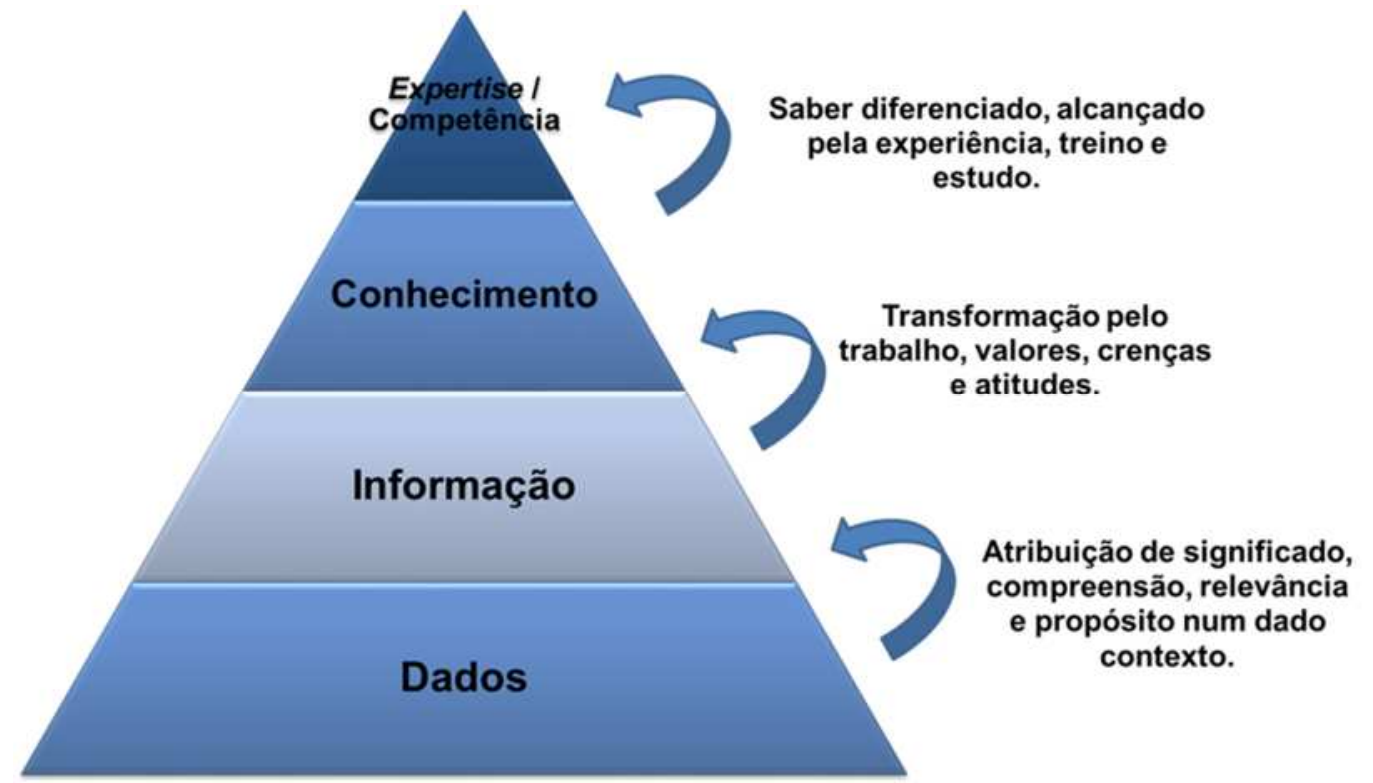

Figura 1: Cadeia de valor do conhecimento

Fonte: Silva, 2013.

A cadeia de valor do conhecimento demonstra claramente o grau de hierarquia entre os respectivos elementos, chegando à expertise ou competência, como último nível de "sabedoria". Somente por meio de sua compreensão, é possível entender os processos da GC e aplicá-los nas organizações.

Nonaka e Takeuchi (2008) explicam que nesta sociedade existem dois tipos de conhecimento, o tácito e o explícito. De acordo com os autores, o conhecimento tácito está armazenado no cérebro do indivíduo e, o conhecimento explícito está contido em documentos, sistemas, processos, disponíveis ao público. Ambos os tipos de conhecimento podem ser produzidos 
como resultados de inovações ou interações, assim como são considerados pelos teóricos da GC, como a base de entendimento para sua visão holística. O Quadro 1 ilustra as propriedades dos conhecimentos tácito e explícito:

Quadro 1: Propriedades do conhecimento tácito e explícito.

\begin{tabular}{|c|c|}
\hline Propriedades do conhecimento tácito & Propriedades do conhecimento explícito \\
\hline $\begin{array}{l}\text { 1. Capacidade de adaptação para lidar com } \\
\text { situações novas e excepcionais. }\end{array}$ & $\begin{array}{l}\text { 1. Capacidade de disseminar, reproduzir, para } \\
\text { acessar e renovar toda a organização. }\end{array}$ \\
\hline 2. Expertise, know-how, knowwhy e care-why. & 2. Capacidade para ensinar, para treinar. \\
\hline $\begin{array}{l}\text { 3. Capacidade de colaborar, de compartilhar } \\
\text { uma visão, para transmitir uma cultura. }\end{array}$ & $\begin{array}{l}\text { 3. Capacidade de organizar, sistematizar, para } \\
\text { traduzir uma visão em uma declaração de } \\
\text { missão, em diretrizes operacionais. }\end{array}$ \\
\hline $\begin{array}{l}\text { 4. Coaching e mentoringpara transferir } \\
\text { conhecimento experiencial em uma base } \\
\text { one-to-one, face-a-face. }\end{array}$ & $\begin{array}{l}\text { 4. Transferência de conhecimento por meio de } \\
\text { produtos, serviços e processos documentados. }\end{array}$ \\
\hline
\end{tabular}

Fonte:Dalkir, 2005.

Uriarte (2008) ressalta que não há uma definição universalmente aceita para o termo "gestão do conhecimento", embora se possam definir algumas das mais usuais nesta nova sociedade. Terra (2000, p.70) conceitua GC como "a capacidade de utilizar e combinar as várias fontes e tipos de conhecimentos para que se desenvolvam competências específicas e capacidade inovadora, que se traduzem permanentemente, em novos produtos, processos e sistemas gerenciais”. Essa definição é semelhante à de outros autores, como Wiig (1993); Sveiby (1997); Liebowitz e Wilcox (1997 apud STEIL, 2007); O’Leary (1998 apud STEIL, 2007); Davenport e Prusak (1998) e outros, como ilustra o Quadro 2:

Quadro 2: Abordagens da GC.

\begin{tabular}{|l|l|}
\hline \multicolumn{1}{|c|}{ Autor(es) } & \multicolumn{1}{c|}{ Abordagens da Gestão do Conhecimento } \\
\hline Wiig (1993) & $\begin{array}{l}\text { A gestão do conhecimento faz com que a organização atua de forma } \\
\text { mais inteligente, facilitando a criação, acumulação, desenvolvimento e } \\
\text { uso de conhecimento de qualidade. }\end{array}$ \\
\hline Sveiby (1997) & GC é a arte de criar valor alavancando os ativos intangíveis. \\
\hline $\begin{array}{l}\text { Liebowitz e Wilcox } \\
(1997)\end{array}$ & $\begin{array}{l}\text { Habilidade das organizações para gerenciar, armazenar, agregar valor e } \\
\text { distribuir conhecimento }\end{array}$ \\
\hline O'Leary (1998) & $\begin{array}{l}\text { Gerenciamento formal do conhecimento para facilitar a criação, o } \\
\text { acesso, e a reutilização do conhecimento, geralmente com a utilização } \\
\text { de tecnologia da informação }\end{array}$ \\
\hline $\begin{array}{l}\text { Davenport e Prusak } \\
(1998)\end{array}$ & $\begin{array}{l}\text { A gestão do conhecimento é o conjunto de processos que visam } \\
\text { determinar a criação, disseminação e utilização do conhecimento } \\
\text { (organizacional) para atender aos objetivos organizacionais. }\end{array}$ \\
\hline
\end{tabular}

Fonte:Autor, 2015. 
Rossetti e Morales (2007) relatam que a GC envolve o gerenciamento de ativos intangíveis de diferentes naturezas: pessoas, conhecimentos tácitos, explícitos, individuais, organizacionais e de redes, assim como compreendem os conhecimentos estruturais, que servem de base tecnológica para armazenar, codificar e disseminar o fluxo dos bens intangíveis. Para Correia e Sarmento (2003), o papel fundamental da GC é o de transformar o conhecimento individual em conhecimento coletivo.

\subsection{Processos em gestão do conhecimento}

A GC aborda uma série de modelos teóricos que buscam criar, disseminar e usar o conhecimento como fator estratégico para as organizações, de modo a facilitar e organizar informações para a tomada de decisão. Em suma, é uma sequência de passos que aumenta o poder de contribuição do conhecimento.Segundo Dalkir (2005) um dos principais processos da GC tem como objetivo identificar e localizar o conhecimento e fontes de conhecimento dentro das organizações. Como forma de promover a disseminação do conhecimento gerado, adotamse ferramentas como redes, práticas e incentivos para estimular as pessoas a transferir conhecimento, tomar decisões e resolver problemas.

São diversos os modelos de GC que descrevem os processos de criação, organização e disseminação do conhecimento, como por exemplo os de: Wiig (1993), Nonaka e Takeuchi (1995), Von Krogh e Roos (1995), Choo (1998), Bukowitz e Williams (2000), Weick (2001), McElroy (2003) e Bennet e Bennet (2004).Contudo, um dos mais conhecidos e adotados pelas organizações é o modelo SECI, que se baseia no processo de criação do conhecimento por meio da Espiral de Conhecimento propostas por Nonaka e Takeuchi (1995). Esse modelo descreve a forma como os conhecimentos tácito e explícito são ampliados em termos de qualidade e quantidade, assim como do indivíduo para o grupo e, para o nível organizacional, ilustrado na Figura 2: 


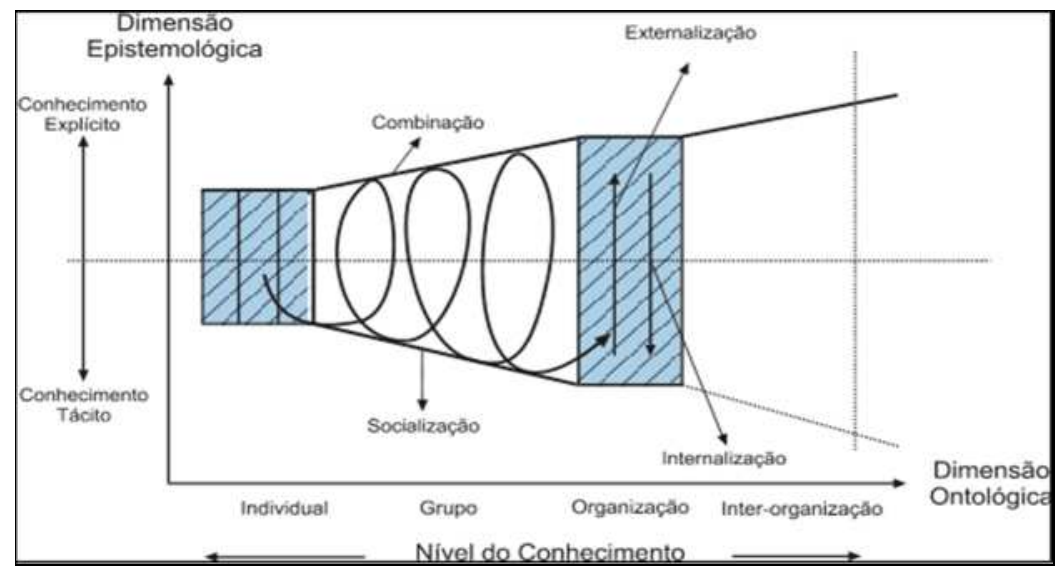

Figura 2: Espiral do conhecimento organizacional Fonte:Nonaka; Takeuchi, 1997, p. 62.

A criação do conhecimento tácito pode, inclusive, ocorrer de forma inesperada ou não planejada. De acordo com Nonaka e Takeuchi (2008), existem quatro modos de conversão do conhecimento, que constituem seu motor de criação a partir das experiências individuais. A combinação dessas categorias permite converter o conhecimento explícito e tácito em quatro padrões distintos, criando novos conhecimentos - Socialização, Externalização, Combinação e Internalização.

A socialização consiste em compartilhar o conhecimento de indivíduo para indivíduo, por meio das interações sociais. A externalização converte o conhecimento tácito em explícito, por meio de "metáforas, analogias, conceitos, hipóteses ou modelos" (NONAKA; TAKEUCHI, 1995, p. 4 apud DALKIR, 2005, p. 54).A combinação é o processo de modificar o conhecimento explícito já existente em outras formas, originando conhecimentos mais apurados.A internalização converte ou integra experiências compartilhadas ou conhecimentos individuais em modelos mentais individuais. Em síntese, a Figura 3 ilustra os quatro quadrantes: 


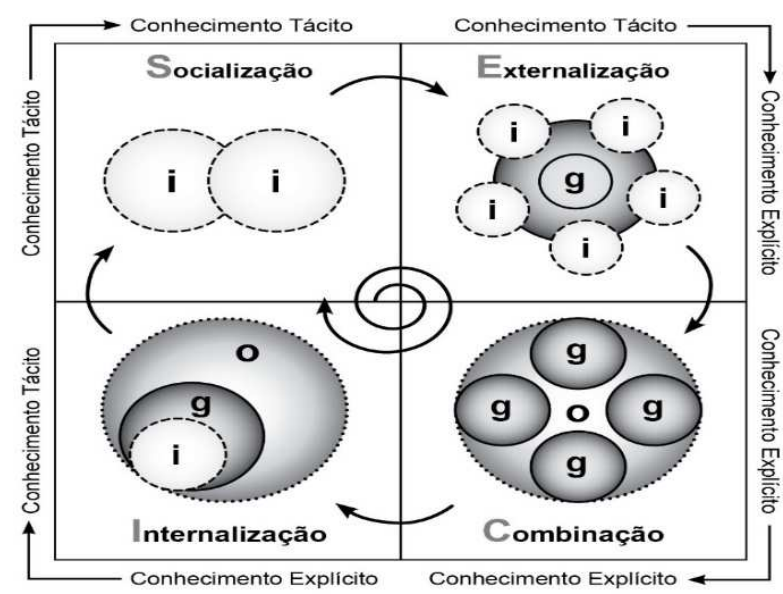

(i) indivíduo (g) grupo organização

Figura 3: Evolução da espiral do conhecimento - Modelo SECI Fonte:Nonaka; Konno, 1998.

A espiral do conhecimento é uma atividade contínua de fluxo de conhecimento, partilha e conversão por parte dos indivíduos, comunidades e da própria organização. Ao finalizar os quatros quadrantes, o processo recomeça em um nível superior, fazendo crescer a espiral de conhecimento e gerando novos conhecimentos.

Uriarte (2008) ressalta a importância dos processos completos de GC para visualizar seu funcionamentona organização e que, segundo o autor, requer quatro elementos: a) criação e captura do conhecimento, b) compartilhamento do conhecimento, c) armazenamento e recuperação do conhecimento e d) disseminação do conhecimento.

O modelo de Wiig (1993) integra também quatro fases, na qual baseia-se em três condições para o sucesso dos negócios: deve ter produto ou serviço e consumidores; recursos (pessoas e capital); e habilidade para atuar no mercado. Seu ciclo é assim constituído: a) construção do conhecimento, b) segurança do conhecimento, c) agrupamento do conhecimento e d) aplicação do conhecimento. Dalkir (2005) explica que os principais ciclos da gestão do conhecimento não estão ainda bem definidos. As diferenças entre eles não são muito grandes, e algumas vezes estes ciclos se sobrepõem. Mesmo assim, é importante adotar um processo para a criação, compartilhamento, armazenamento e disseminação do conhecimento, haja vista ser este o principal objetivo da GC. Oautor salienta que o conhecimento representa a base decisiva para um comportamento inteligente, tanto do indivíduo, da organização e dos grupos de práticas. As melhores práticas aprendidas no processo de criação e codificação do conhecimento possibilitarão a criação de produtos de informação a serem utilizados pelos membros 
envolvidos. No entanto, é preciso compartilhar desse conhecimento com um público amplo, apoiando-se em ferramentas de TIC`s como groupware, intranets, bases de dados, repositórios de dados e informações. Essas ferramentas vêm a contribuir para os trabalhadores do conhecimento tornarem-se membros ativos e participantes do ciclo da GC (SILVA, 2013).

\section{Resultados}

Os resultados da pesquisa integram a revisão narrativa da literatura, com as principais contribuições da GC para a gestão das empresas turísticas. Tais contribuições podem alicerçar outras empresas no âmbito da gestão estratégica do turismo, valorizando o conhecimento do cliente, a aprendizagem organizacional e o estímulo ao gestor para aplicar as ferramentas de GC já implementadas, em um processo de benchmarking. O Quadro 3 sumariza as principais contribuições das pesquisas empíricas e teóricas sobre a GC aplicada às organizações turísticas selecionadas para este estudo.

Dentre os nove artigos analisados, identificou-se que há uma evolução cronológica das publicações sobre o tema 'gestão do conhecimento e o turismo' (Quadro 3), com predominância dos estudos realizados na Ásia e Europa respectivamente. Entretanto, percebe-se como o assunto ainda é pouco discutido no âmbito do turismo e, ainda, escassa a implementação da GC em empresas do setor. Os artigos analisados demonstram que estudos empíricos já se equilibram com estudos teóricos, nos quais cinco deles demonstram cases de sucesso.

Quadro 3: Sumário das publicações selecionadas

\begin{tabular}{|c|c|c|c|c|}
\hline Autor (es) & Propósito da publicação & Journal & Ano & Origem \\
\hline $\begin{array}{l}\text { Pyo, Uysal e } \\
\text { Chang }\end{array}$ & $\begin{array}{l}\text { O artigo apresenta os recursos do KDD como } \\
\text { ferramenta de apoio na codificação e no } \\
\text { armazenamento de dados turísticos a fim de aplicá- } \\
\text { los à Ilha de Cheju e beneficiar o turismo local que } \\
\text { encontrava-se estagnado. }\end{array}$ & $\begin{array}{c}\text { Journal of } \\
\text { Travel } \\
\text { Research }\end{array}$ & 2002 & $\begin{array}{l}\text { Coréia } \\
\text { do Sul }\end{array}$ \\
\hline $\begin{array}{l}\text { Ruhanen e } \\
\text { Cooper }\end{array}$ & $\begin{array}{l}\text { O estudo demonstra a importância da pesquisa } \\
\text { como subsídio da GC. Incentiva a valorização e o } \\
\text { aumento do capital intelectual e da equidade na } \\
\text { indústria do turismo. Considera que, com } \\
\text { investimentos em pesquisa, o turismo poderá ser } \\
\text { mais competitivo e sustentável. }\end{array}$ & $\begin{array}{l}\text { Tourism } \\
\text { Recreation } \\
\text { Research }\end{array}$ & 2004 & Austrália \\
\hline Pyo & $\begin{array}{l}\text { O autor demonstra como a ferramenta "mapa do } \\
\text { conhecimento" pode ser útil na prática da GC, na } \\
\text { criação e na transferência do conhecimento com } \\
\text { baixos custos. Salienta-se ainda que os mapas } \\
\text { devem ser construídos segundo as necessidades do } \\
\text { destino turístico. }\end{array}$ & $\begin{array}{c}\text { Tourism } \\
\text { Management }\end{array}$ & 2005 & $\begin{array}{l}\text { Coréia } \\
\text { do Sul }\end{array}$ \\
\hline
\end{tabular}




\begin{tabular}{|c|c|c|c|c|}
\hline $\begin{array}{l}\text { Canina, Enz } \\
\text { e Walsh }\end{array}$ & $\begin{array}{l}\text { A investigação centrou-se em } 563 \text { hotéis nos } \\
\text { Estados Unidos, com o objetivo de identificar como } \\
\text { eles poderiam criar valor por meio de seus } \\
\text { investimentos em capital intelectual. Concluiu-se } \\
\text { que empresas hoteleiras que investirem em seu staff } \\
\text { terão mais desempenho organizacional e satisfação } \\
\text { por parte deles. }\end{array}$ & $\begin{array}{c}\text { Cornell } \\
\text { Hospitality } \\
\text { Report }\end{array}$ & 2006 & $\begin{array}{l}\text { Estados } \\
\text { Unidos }\end{array}$ \\
\hline Cooper & $\begin{array}{l}\text { O estudo demonstra vários modelos teóricos de GC } \\
\text { que podem ser aplicados ao campo do turismo, bem } \\
\text { como as barreiras existentes para essa gestão. Um } \\
\text { dos aspectos relevantes é a possibilidade de } \\
\text { adaptação de modelos consagrados da área de GC } \\
\text { para o turismo, assim como o reconhecimento do } \\
\text { conhecimento tácito como premissa de valor neste } \\
\text { segmento. }\end{array}$ & $\begin{array}{c}\text { Annals of } \\
\text { Tourism } \\
\text { Research }\end{array}$ & 2006 & Austrália \\
\hline $\begin{array}{l}\text { Hallin e } \\
\text { Marnburg }\end{array}$ & $\begin{array}{l}\text { O artigo traz um conjunto de estudos empíricos de } \\
\text { GC no campo da hospitalidade. Seus principais } \\
\text { aspectos são abordados na aprendizagem } \\
\text { organizacional, nas melhores práticas, na } \\
\text { transferência de conhecimento, no reconhecimento } \\
\text { da TI como recurso de valor para o turismo e na GC } \\
\text { como vantagem competitiva. }\end{array}$ & $\begin{array}{c}\text { Tourism } \\
\text { Management }\end{array}$ & 2008 & Noruega \\
\hline $\begin{array}{l}\text { Shaw e } \\
\text { Williams }\end{array}$ & $\begin{array}{l}\text { Os autores revisam a pesquisa atual sobre GC e sua } \\
\text { transferência no contexto da inovação no campo do } \\
\text { turismo. Concluiu-se que dentre os segmentos do } \\
\text { turismo, a hotelaria se apresenta como mais } \\
\text { promissora na transferência de conhecimento. } \\
\text { Ainda, o artigo chama a atenção para se considerar } \\
\text { as inovações no turismo como pertencente à GC. }\end{array}$ & $\begin{array}{c}\text { Tourism } \\
\text { Management }\end{array}$ & 2009 & $\begin{array}{l}\text { Reino } \\
\text { Unido }\end{array}$ \\
\hline Anjos et al. & $\begin{array}{l}\text { O artigo buscou evidenciar a GC como diferencial } \\
\text { competitivo para os serviços de destinos turísticos. } \\
\text { O estudo realizou-se em uma agência de viagens em } \\
\text { Foz do Iguaçu (BR). Suas conclusões se pautaram } \\
\text { na aprendizagem organizacional, no } \\
\text { reconhecimento do conhecimento do consumidor e } \\
\text { na GC como gestão estratégica. }\end{array}$ & $\begin{array}{c}\text { Estudios y } \\
\text { Perspectivas } \\
\text { en Turismo }\end{array}$ & 2011 & Brasil \\
\hline $\begin{array}{l}\text { Paraskevas } \\
\text { et al. }\end{array}$ & $\begin{array}{l}\text { O estudo propõe a governança de crises no } \\
\text { segmento de turismo por meio da GC. A gestão } \\
\text { eficaz do conhecimento melhora a capacidade de } \\
\text { resistência dos destinos turísticos em situações de } \\
\text { crise. O estudo A pesquisa se baseou em teorias } \\
\text { sobre gestão de crises e, também, em descrever } \\
\text { como os fluxos de conhecimento institucionalizado } \\
\text { podem responder às crises da organização, visando } \\
\text { a experimentação e a geração de novos } \\
\text { conhecimentos. }\end{array}$ & $\begin{array}{l}\text { Annals of } \\
\text { Tourism } \\
\text { Research }\end{array}$ & 2013 & $\begin{array}{l}\text { Reino } \\
\text { Unido }\end{array}$ \\
\hline
\end{tabular}

Fonte:Autor, 2015. 


\subsection{Síntese do conhecimento}

A síntese do conhecimento apresenta-se como sendo a última etapa da revisão, cuja exposição se faz com as ideias principais das publicações analisadas. Dessa forma, para cada uma das nove publicações, criou-se uma sumarização, segundo a sequência em que foram apresentadas suas referências no Quadro 3, em uma sequência cronológica:

Pyo, Uysal e Chang (2002) em Knowledge Discovery in Database for Tourist Destinations apresentam um estudo de caso nas Ilhas Cheju, Coréia do Sul. Segundo os autores, o destino turístico passou por uma estagnação em relação ao número de visitantes e consequentemente arrecadação de renda proveniente do turismo. Os dois principais motivos foram: a crise financeira devido à escassez de moedas estrangeiras na Coréia e no Fundo Monetário Internacional e, a competição com a região de Keumkang Montanha da Coréia do Norte. Uma das alternativas para aumentar o número de visitantes e sua permanência na Ilha foi decidida pelo Departamento de Turismo de Cheju pelos recursos do Knowledge Discovery in Database (KDD), ou seja, a mineração de dados como ferramenta da GC.Um número suficiente de dados com variáveis centradas nos problemas de Cheju foram armazenados em um banco de dados e, a partir deles, estratégias foram tomadas, como desenvolver novas atrações para a Ilha e novos nichos de mercado, além de fornecer informações aos visitantes sobre a Ilha, para que repassassem a familiares e amigos, visando aumentar a demanda. Para Pyo, Uysal e Chang (2002), o turismo, a pesquisa e a tecnologia da informação são competências fundamentais para o desempenho de um destino turístico. O KDD apoia a codificação e o armazenamento dos dados turísticos a fim de aplicá-los ao destino, pensando em uma posição estratégica. O destino pode usar o conhecimento para determinar a estratégia e táticas de marketing em tempo real, como desenvolver alterações no local e propor novas demandas turísticas, com o apoio da tecnologia (PYO; UYSAL; CHANG, 2002).

Runhanen e Cooper (2004), em Applying a Knowledge Management Framework to Tourism, apresentam uma visão geral do conceito de GC e seus problemas na aplicação ao campo do turismo. Segundo os autores, a GC é condição essencial para o desenvolvimento da Pesquisa e Inovação dentro das empresas e, o turismo não tem sido abordado como campo de pesquisa em GC. Talvez por este motivo, o segmento passa a não ser tão competitivo como poderia, especialmente em destinos ainda não consolidados. Um bom exemplo, citado pelos autores, é que muitas organizações turísticas (hotéis, restaurantes, operadoras, eventos entre outros) não conhecem o mercado, seus concorrentes e seus consumidores por falta de 
informações e, por não valorizar o potencial da pesquisa de mercado e de satisfação, acabam declinando em seu ciclo de vida. O framework desenvolvido por Ruhanen e Cooper (2004) evidencia que a abordagem da GC deve ser o objetivo para futuros planos de investigação, visando o aumento do capital intelectual e da equidade na indústria do turismo. A experiência dos estudos na Cooperative Research Centre for Sustainable Tourism (CRC ST)na Austrália demonstrou o potencial para gerar resultados comerciais a partir de investimentos em pesquisa, sendo uma de suas áreas de interesse o processo de integração da pesquisa em GC à pesquisa ao turismo.

Pyo (2005), em Knowledge map for tourist destinations: needs and implications, traz o conceito de mapas do conhecimento aplicado às destinações turísticas. Segundo o autor, mapas de conhecimento são modelos para ajudar a encontrar o conhecimento, por meio da representação visual (círculos ligados por linhas de imagens), bem como a conceituação de hierarquias de dados e informações a partir de suas ligações. Ademais, busca-se obter uma visão global sobre as fontes de informação disponíveis. O objetivo do estudo foi debater os processos de mapeamento do conhecimento no sistema de GCem diferentes tipos de destinos turísticos da Coréia. As cidades selecionadas foram: Seul, Seolak, Kyongju e Cheju. O autor concluiu em sua pesquisa que o mapa do conhecimento é uma ferramenta útil para definir o conhecimento sobre as necessidades do destino durante o estágio inicial do sistema de GC. Ele apoia a tomada de decisão em tempo real e auxilia os gestores a eliminar a duplicação de esforços para encontrar o mesmo conhecimento. Pyo (2005) alega que o conhecimento quando compartilhado cresce exponencialmente e contribui para a produtividade da indústria turística. Os mapas podem ser comparados e podem ter diferentes estruturas por parte da indústria e / ou bases de dados regionais de conhecimento. Contudo, é necessário compreender que cada destino e cada organização apresentam formas específicas para as suas próprias necessidades.

O estudo realizado por Enz, Canina e Walsh (2006), em Intellectual Capital: A Key Driver of Hotel Performance, buscou identificarem 563 hotéis nos Estados Unidos como tais empreendimentos podem criar valor por meio de seus investimentos em capital intelectual. Os autores defendem que esses investimentos têm tido o maior impacto na rentabilidade de empreendimentos ligados ao turismo. No estudo, os autores destacam os principais componentes identificados, alusivos à GC. São eles: a) conhecimento do capital humano, ou seja, valorização das habilidades e experiências dos colaboradores; b) capital de sistemas (conhecimento operacional da empresa), incluindo processos, políticas e procedimentos, e c) 
capital de cliente, valorizando a marca e o poder de atração e retenção de clientes. Finalmente, puderam concluir por meio dos resultados, que o investimento em capital intelectual é um fator essencial para o desempenho financeiro de um hotel.Hotéis que investir em seus funcionários da linha de frente tendem a ter maior desempenho em vários aspectos, sobretudo, no financeiro. Cooper (2006), em Knowledge management andtourism, centrou-se em alguns modelos de GC que podem ser aplicados no turismo, incluindo na discussão de literatura os autores mais reconhecidos na área como Davenport e Prusak (1998), Pyo, Uysal e Chang (2002), Davidson e Voss (2002), Nonaka e Takeuchi (1995) entre outros. Contudo, uma das ideias centrais ressalta que qualquer modelo adotado deve se alinhar à organização turística e contribuir para sua gestão. A literatura oferece uma série de modelos possíveis, mas a sua raiz, segundo Davidson e Voss (2002) são os chamados stocks e flows de pesquisa. As ações (stocks) são as coisas que são conhecidas e os fluxos (flows) são o meio pelo qual o conhecimento é comunicado para aqueles que dele necessitam. Esse modelo funciona bem para o turismo e oferece insights e técnicas práticas para facilitar a transferência do conhecimento no campo do turismo (COOPER, 2006). O estudo aborda também as barreiras de aplicação da GC no turismo. Em síntese, a conclusão do autor mostrou o potencial da aplicação das perspectivas teóricas de GCpara os pesquisadores de turismo. Estes incluem a importância do reconhecimento do conhecimento tácito nas organizações e a possibilidade de adaptação de modelos para o campo do turismo. Cooper (2006) tentou rever ideias, alegando que a disseminação do conhecimento flui dentro de um modelo de gestão do conhecimento.

Hallin e Marnburg (2008), em Knowledge management in the hospitality industry: A review of empirical research, apresentam o primeiro estudo sobre o estado da arte em pesquisa empírica de GC no campo da hospitalidade. Foram identificados 19 artigos e analisados sob a perspectiva dinâmica do conhecimento. Sheldon (1997 apud HALLIN; MARNBURG, 2008) inicialmente argumenta que a indústria do turismo e da hospitalidade é uma das maiores usuárias de tecnologia da informação (TI). Na investigação, os autores dividiram os 19 artigos em três categorias distintas: a primeira se concentra na aplicação da GC na indústria do turismo (3), a segunda está centralizada em questões inter-organizacionais entre destinos (4) e, a terceira corrente de pesquisa, adota uma abordagem voltada a perspectiva intra-organizacional de negócios (12). Hallin e Marnburg (2008) concluíram que a GC no campo da hospitalidade tem revelado potencialidades e obstáculos para as empresas da área. Em contrapartida, evidenciam que a GC é altamente relevante para a criação de vantagem competitiva. Na visão dos autores, 
o turismo é resultado do uso intensivo da TI e do serviço, haja vista que esses se baseiam na interação entre funcionários do segmento e clientes intensivos em conhecimento. Por isso, as percepções dos hóspedes/visitantes sobre a qualidade do serviço são aspectos fundamentais para a GC. Além disso, empresas ligadas à hospitalidade podem se beneficiar dos sistemas de GC em relação ao desenvolvimento de redes de conhecimento entre os clusters de empresas de turismo. No entanto, o segmento de turismo e hospitalidade está muito aquém quando se trata dos esforços empreendidos nas práticas de GC. Relatam ainda que existe uma grande necessidade de estudos empíricos no campo do turismo, a fim de contribuir para uma discussão global das práticas da GC na indústria do turismo e da hospitalidade.

Shaw e Williams (2009), em Knowledge transfer and management in tourism organisations: Anemerging research agenda, discutem alguns dos principais paradigmas sobre vantagem competitiva na perspectiva do conhecimento ao nível da empresa. Seus estudos são teóricos e, à medida em que trazem conceitos de GC e suas nuances, introduzem a transferência do conhecimento no turismo. Ao longo do artigo, exemplos de práticas de gestão de transferência do conhecimento são mais evidentes. Na discussão da literatura, elucidam o capital intelectual como vantagem competitiva, citados por Enz, Canina e Walsh (2006) para as redes hoteleiras. Os autores explicam que uma das vantagens competitivas resultantes da transferência de conhecimento é o papel desempenhado pelo investimento exterior e a troca de conhecimentos entre organizações transnacionais. Esta dinâmica pode redistribuir ou reutilizar o conhecimento existente dos países em transação, mais uma vez com especial atenção ao reconhecimento do conhecimento tácito.Shaw e Williams (2009) concluíram em sua revisão de literatura a necessidade de integrar os conceitos de GC em todas as áreas do turismo. Destacam o trabalho desenvolvido por Ruhanen e Cooper (2003), em que sugerem umacadeia de valor do conhecimento para o setor do turismo. Contudo, ressalvam que o protótipo ainda não fora testado. Finalmente, enfatizam a importância do conhecimento como motor de inovação e competitividade para o turismo, novamente reconhecendo o conhecimento tácito como vetor de transformação.

O estudo de Anjos et al. (2011), em Contribuciones de La gestión Del conocimiento a los servicios turísticos: estúdio en una agencia de viajes, apresenta uma revisão da literatura sobre práticas da GC como fator de diferenciação para o desenvolvimento estratégico de empresas turísticas. Além disso, descreve o estudo de caso de uma agência de viagens e turismo localizada no município de Foz do Iguaçu, Paraná, Brasil.No estudo, as ferramentas de GC 
foram verificadas segundo um modelo de análise já aplicado em uma agência de viagens e turismo do grupo Naipi Turismo e Eventos do respectivo destino.A pesquisa revelou que a agência de viagens analisada apresenta limitações com relação à aplicação da GC e, entre elas, destacam-se o turnover de funcionários e a ausência de implementação de processos de GC. Um dos pontos capitais apresentados pelos autores, foi a inexistência darelação de confiança entre os colaboradores na troca de informações, ocasionada talvez, pela concorrência interna por clientes preferenciais. Os autores concluíram que investimentos em qualificação profissional pode favorecer o relacionamento entre colegas de trabalho e fornecedores, melhorando a capacidade de inovação e de gestão, baseada nas relações de confiança.

O estudo de Paraskevas et al. (2013) em Crisis Knowledge in Tourism: Types, Flows and Governance discute a gestão de crises no campo do turismo e a contribuição da GC para gerenciar as diversas situações que, por vezes, colocam em risco a competitividade das empresas turísticas. Cooper (2006) explica que a GC com suas abordagens pode favorecer o gerenciamento de crises em períodos de adaptação organizacional, mudanças externas e crises frequentes, haja vista ser este um segmento cada vez mais exposto a tensões. A pesquisa pretendeu identificar um gap na literatura, ao explorar como a GC pode contornar uma crise em empresas do turismo, empregando os fatores organizacionais: liderança, estrutura, cultura e comunicação em processos de influência. A pesquisa empírica foi realizada com 21 executivos de hotéis que ocupavam posição de direção na empresa, ou estavam diretamente envolvidos com as decisões relacionadas com a gestão de risco / crises.A principal conclusão do estudo foi de natureza procedural, em que o conhecimento sozinho pode tornar-se problemático em situações de crises, uma vez que não permite flexibilidade e diversas percepções. Em gestão de crises, os conhecimentos tácitos e explícitos devem integrar-se às situações da empresa. Os autores propuseram ainda um framework para tipos de crises em organizações turísticas, buscando trabalhar a resiliência nas organizações.

\section{Considerações Finais}

Em vista das perspectivas práticas da GC aplicadas às organizações turísticas, reconhece-se que, de modo geral, trata-se de um campo de estudo de gestão emergente, mas que aos poucos se apropria deste novo paradigma. Percebeu-se nos artigos analisados, o reconhecimento da importância da pesquisa, do estudo da percepção, dos ativos intangíveis, do capital intelectual, 
das TIC`s e outras ferramentas como apoio decisório para as empresas turísticas. Ainda, a interação sociocultural e ambiental dos diversos stakeholders ao ambiente, permitem a interação com vistas à criação, compartilhamento e disseminação do conhecimento (AHMED, LIM, LOH, 2002; COOPER et al., 2007; HALLIN, MARNBURG, 2008).

O papel da GC é garantir competitividade e eficiência aos processos organizacionais, por meio da criação, armazenamento, compartilhamento e utilização dos conhecimentos tácito e explícito, de forma inovadora para todo tipo de organização. É notável que o sucesso de qualquer empreendimento depende da participação e articulação de seus stakeholders e, sobretudo, de suas percepções sobre os processos gerenciais. No caso do turismo, deve-se assegurar que as expectativas e necessidades dos clientes/visitantes sejam conhecidas e consideradas como aspectos estratégicos de melhoria contínua. De modo geral, essas expectativas envolvem satisfação de necessidades, compensação financeira e comportamento ético e hospitaleiro.

Os resultados dos estudos teóricos e práticos da GC no campo do turismo demonstram que esta forma de gestão sustentada pela pesquisa e suas diversas ferramentas de apoio, podem alavancar substancialmente a qualidade dos serviços turísticos, assim como a gestão da empresa ou destino turístico. Ao implementar os preceitos da GC, as organizações tendem a melhorar o aumentoda demanda, identificar fraquezas e oportunidades, desenvolver novos produtos e processos, contribuir para a aprendizagem organizacional, cuja finalidade é agir estrategicamente entre as organizações do segmento do turismo.O turismo é um "serviço de experiência" para os indivíduos e, portanto, difere dos bens tangíveis quando julgado seu valor no mercado de serviços, como afirmam Cooper et al. (2007). Por isso, ele deve ser planejado sobre outro prisma, preconizando serviços de excelência e ações humanizadas, buscando o conhecimento contextualizado nas dimensões econômica, social, cultural, ambiental e também científica para a tomada de decisão assertiva.

O objetivo da pesquisa foi alcançado, na perspectiva em analisar como a GC pode contribuir para a competitividade das organizações turísticas. O estudo teórico revela inúmeras possibilidades de reflexão, especialmente quando se encontra na literatura casos reais de aplicação de modelos. Ademais, compreende-se o quão é necessário conhecer novas formas de gestão, a fim de eleger ferramentas que possam ser replicadas em empresas do segmento, buscando sobreviver às crises e melhorar a competitividade. Em relação à limitação da pesquisa, o número escasso de artigos restringe análises e conclusões mais apuradas. Por um 
lado, percebe-se ser este um tema incipiente, mas com possibilidades crescentes de disseminação no segmento de turismo, especialmente pelo enfoque ao capital intelectual, ao reconhecimento dos conhecimentos tácitos e explícitos. Por outro lado, a escassez de estudos indica também que a GC ainda é um paradigma novo, pouco conhecido e aplicado pelas organizações turísticas, em especial no Brasil.

Recomenda-se, a partir desse estudo, criar redes de colaboração e reflexão entre pesquisadores e empresários do setor de turismo, sobre formas de implementar a GC nas organizações turísticas, especialmente no Brasil, onde a prática ainda é embrionária.

\section{Referências}

ANJOS, F. A. et al. Contribuciones de la gestión del conocimiento a los servicios turísticos estudio en una agencia de viajes. Estudios y Perspectivas en Turismo, vol. 20, p. 722-737, 2011.

ARMED, P. K.; LIM, K. K.; LOCH, A.Y.E. Learning through knowledge management .Butterwoth Heinemann: Oxford, 2002.

BEESLEY, L. The management of emotion in collaborative tourism research settings. Tourism Management, vol.26, p. 261-275, 2005.

BOTELHO, L. L. R., CUNHA, C. C. de A., MACEDO, M. O método da revisão integrativa nos estudos organizacionais. Gestão e Sociedade, vol.5, n.11, p.121-136, 2011.

BUKOWITZ, W.; WILLIAMS, R. The Knowledge Management Field Book. London: Prentice Hall, 2000.

CHOO, C.W. The Knowing Organization. Oxford: Oxford Press University, 1998.

COOPER, C. et. al. Turismo: princípios e práticas. Trad. de Alexandre Salvaterra. 3.ed. Porto Alegre: Bookman, 2007.

COOPER, C. Knowledge management and tourism. Annals of Tourism Research, vol. 33, n. 1, p.47-64, 2006.

COOPER, C.; RUHANEN, L. Applying a Knowledge Management Framework to Tourism Research. Tourism Recreation Research. Luck now, India: Centre for Tourism Research and Development, p.8387, 2004.

CORREIA, A.M. R.; SARMENTO, A. Knowledge Management: key competences and skills for innovation and competitiveness. In: Technology and Human Resource Management International Conference on the Dual Interaction between Technology and Human Resource, Ceram, 2003, Sophie Antipolis. Proceedings...Sophie Antipolis,. p.18-23. 2003

COSTA, N. B. R. da. Impactos socioambientais do turismo em áreas litorâneas: um estudo de percepção ambiental nos balneários de Praia de Leste, Santa Teresinha e Ipanema - Paraná. Revista Geografar, v.6, n.2, p. 151-181, 2011.

DALKIR, K. Knowledge Management in Theory and Practice. Boston: Elsevier, 2005.

DAVENPORT, T. H., PRUSAK, L. Conhecimento empresarial: como as organizações gerenciam seu capital intelectual. 10.ed. Rio de Janeiro: Campus, 2003.

DAVENPORT, T. H.; PRUSAK, L. Conhecimento empresarial. Rio de Janeiro: Campus, 1999. 
DAVENPORT, T. H.; PRUSAK, L. Conhecimento empresarial: como as organizações gerenciam o seu capital intellectual. Rio de Janeiro: Campus, 1998.

DAVIDSON, C.; VOSS, P. Knowledge management. Tandem, Auckland, 2002.

ENZ, C. A.; CANINA, L.; WALSH, K. Intellectual capital: a key driver of hotel performance. Report by Centre of Hospitality Research Cornell University, 2006.

GIL, A. C. Como elaborar projetos de pesquisa. 5.ed. São Paulo: Atlas, 2010.

HALLIN, C. A.; MARNBURG, E. Knowledge management in the hospitality industry: a review of empirical research. Tourism Management, vol.209, p. 366-381, 2008.

HUGHES, J. A filosofia da pesquisa social. Rio de Janeiro: Zahar Editores, 1980.

MORAES, G. D. de A.; TERENCE, A. C. F.; ESCRIVÃO FILHO, E. A tecnologia da informação como suporte à gestão estratégica da informação na pequena empresa. Journal of Information Systems and Technology Management. vol.1, n.1, p 27- 43, 2004.

NONAKA, I., KONNO, N. The Concept of "Ba. Building a foundation for knowledge reation". California Management Review, vol.40, n.3, p. 40-54, 1998.

NONAKA, I.; TAKEUCHI, H. Criação de conhecimento na empresa:como as empresas japonesas geram a dinâmica da inovação. Tradução de Ana Beatriz Rodrigues; Priscila Martins Celeste. Rio de Janeiro: Campus, 1997.

NONAKA, I.; TAKEUCHI, H. Gestão do conhecimento. Trad. de Ana Thorell. Porto Alegre: Bookman, 2008.

PARASKEVAS, A. et al.Crisis Knowledge in Tourism: Types, Flows and Governance, Annals of Tourism Research, vol. 41, p. 130-152, 2013.

PYO, S. Knowledge map for tourist destinations-needs and implications. Tourism Management, n. 26, p. 583-594, 2005.

PYO, S.; UYSAL, M.; CHANG, H. Knowledge discovery in data base for tourist destinations. Journal of Travel Research, vol.40, p. 395-403, 2002.

ROSSETTI, A. G.; MORALES, A. B. T. O papel da tecnologia da informação na GC. Ciência da Informação, Brasília, v. 36, n. 1, p. 124-135, 2007.

ROTHER, E. T. Revisão sistemática x revisão narrativa. Acta Paulista de Enfermagem, São Paulo, v. 20, n. 2, p. v-vi , jun. 2007.

SHAW, G.; WILLIAMS, A. Knowledge transfer and management in tourism organizations: an emerging research agenda. Tourism Management, vol.30, p.325 -335, 2009.

SILVA, M. E. M. Gestão sustentável da orla marítima em destinos turísticos costeiros: a percepção dos atores sociais. (Dissertação) - Programa de Pós-Graduação em Engenharia e Gestão do Conhecimento. Florianópolis, 2013.

STEIL, A. V. Estado da arte das definições de gestão do conhecimento e seus subsistemas. Florianópolis: Instituto Stela, 2007. Technical Report.

STRAUHS, F. do R. et al. Gestão do conhecimento nas organizações. Curitiba: AymaráEduação, 2012. (Série UTFinova).

SVEIBY, K. E. The new organizational wealth: Managing\&measuringknowledge-basedassets.BerrettKoehlerPublishers, 1997.

SVEIBY, K. E. A Nova Riqueza das Organizações: Gerenciando e avaliando Patrimônios de Conhecimento. Editora Campus, Rio de Janeiro, 1998. 
TERRA, J. C. C. Gestão do conhecimento: o grande desafio empresarial”. São Paulo: Negócio Editora, 2000.

URIARTE JR., F. A. Introduction to knowledge management. Jakarta: ASEAN Foundation, 2008.

VON KROGH, G., ROOS, J. Organizational epistemology. New York: St.Martin's Press, 1995.

WEGGEMAN, M.C.D.P. Kennis management: In van kennys intensiv organisaties. Schiedam: Scriptum Management, 1997.

WIIG, K. M. Knowledge management foundations: thinking about how people and organizations create, represent, and use knowledge. Arlington, TX: Schema Press, 1993.

Recebido em: 03/12/2015

Aprovado em: 29/03/2016 